\title{
ESTUDOS DOS GÊNEROS TEXTUAIS: A TRADIÇÃO EM DIFERENTES PERSPECTIVAS NO ENSINO
}

\section{TEXTUAL STUDIES OF GENDER: A TRADITION IN DIFFERENT PERSPECTIVE ON TEACHING}

Resumo: O presente trabalho apresenta-se a partir da necessidade recorrente da exposição de diferentes abordagens sobre o estudo dos gêneros textuais da atualidade. Percorrendo os constructos teórico-metodológicos das Escolas de Sidney, de Genebra e Norte-Americana, procuramos aqui trazer, a partir da consulta da bibliografia dos autores inseridos no campo investigativo das escolas mencionadas, a apresentação da diversidade teórica do campo, bem como as rupturas e deslocamentos daí inerentes.

Palavras-chave: Linguística Textual; Gênero; Ensino.

Abstract: This paper presents from recurring need exposure to different approaches to the study of genres nowadays. Covering theoretical and methodological constructs of Schools Sidney, Geneva and North-American, tried to bring here, from the consultation of the bibliography of the authors included in the investigative field of schools mentioned, the presentation of the theoretical diversity of the field, and the disruptions displacements and hence inherent.

Keywords: Textual Linguistics; gender; Education.

\section{Introdução}

O gênero textual é um campo de estudo considerado multidisciplinar e de diversas perspectivas teóricas e metodológicas voltadas ao ensino em sala de aula e, sendo ele multidisciplinar, nos deparamos com diversas correntes que ora apresentam diferenças, ora semelhanças, bem como novos conceitos a respeito do estudo do gênero. A migração que ocorre em relação ao conceito é decorrente do gênero perpassar por diversas áreas assim, resignifica seu conceito, abrange novas metodologias, desenvolve certa autonomia e principalmente discute novos modelos de estudo.

\footnotetext{
${ }^{1}$ Universidade Tecnológica Federal do Paraná - UTFPR
} 
As tradições que iremos nos referir têm referenciais teóricos distintos, mas defendem uma mesma ideia, essa baseada na teoria do gênero voltada para o ensino de língua. Além de que seu ponto em comum é o de criar uma interação social em que as ações reais de linguagem se realizem e, divergem a respeito nos seus modelos e propostas para o trabalho em sala de aula. Essa comparação se da de modo a refletir os modelos teóricos adotados pelas três escolas que se dedicam ao estudo, a fim de que possamos compreender melhor a evolução dos estudos $e$ as suas diferentes perspectivas.

No Brasil, os gêneros textuais servem como um aparato para o ensino e aprendizagem, a questão é que em muitas vezes esse aparato vem em segundo plano, ao passo que para a Escola de Sidney, de Genebra e a Norte-Americana, focam seus estudos visando o gênero como uma ferramenta essencial no que compete o ensino e aprendizagem, ficando claro que o intuito não é tornar o gênero um objeto de estudo, devido sua "mutação".

Ao que compete às propostas pensadas pelos estudiosos das escolas mencionadas, diversas são as questões norteadoras para o desenvolvimento de uma metodologia e de um aporte teórico, referente ao estudo do gênero como sendo uma prática a ser ensinada em sala de aula. Algumas questões levantadas como: Porque devemos estudar os gêneros? Como devemos estuda-los? Qual a importância do estudo do gênero para a prática pedagógica? Quais gêneros, já que eles são múltiplos e heterogêneos, devem ser objetos de ensino na escola? Como organizá-los em uma progressão que leve em conta o desenvolvimento e a aprendizagem dos alunos? O que fazer com a tipologia clássica (narração, descrição, dissertação) que predomina na escola e já faz parte dos saberes escolares? Entre esses questionamentos encontram-se: Halliday, Jim Martin, Joan Rothery, Frances Christie (Escola de Sidney), Bernard Schneuwly, Joaquim Dolz, Jean-Paul Bronkcart (Escola de Genebra), Miller, John Swales, Charles Bazerman (Escola Norte-Americana), entre outros. Segundo Bunzen (2003) com essas diferenças encontradas nessas tradições, estaríamos fazendo com que tenhamos 
outros caminhos para o estudo de gênero e sua aplicação no ensino, uma vez que os gêneros aportam uma alternativa para as práticas pedagógicas "tradicionais".

\section{A escola de Sidney}

A Escola de Sidney é a percussora na relação entre gênero e ensino de língua materna e estrangeira, segundo Bunzen (2004), a origem desses estudos remonta as décadas de 1970 e 1980, época em que se realizavam pesquisas sobre as práticas de letramento nas escolas australianas. Os estudos propostos por essa escola foram baseados na Linguística Sistêmico-Funcional proposta por Halliday. Esse aporte teórico advém da sociologia da educação e práticas de letramento escolar.

O conceito de gênero e de seu modelo para o ensino está relacionado ao conceito de cultura e de situação, ou seja, para o conceito de cultura o objetivo social do texto passa pela ideologia, pelas convenções sociais e pelas instituições, devido à crença de que é no contexto da cultura que se desenvolve o gênero, que nessa perspectiva configura-se como "um sistema estruturado em partes, com meios específicos e fins específicos" (VIAN JR, LIMA-LOPES, 2005 p. 29), ao passo que para o conceito de situação ou de registro, corresponde à realização imediata do texto que comporta as relações e estruturas, bem como a organização simbólica da linguagem.

Dessa forma, pensando na proposta de uma melhor organização do trabalho do professor, os estudiosos de Sidney formularam um ciclo de ensino de gênero composto pelos seguintes estágios: negociação do campo (tópico), desconstrução, construção conjunta e a construção independente.

\section{A escola Norte-Americana}

Também conhecida por Escola Nova Retórica, deixa de lado a proposta de uma forma de ensino que partiria dos estudos retóricos, assim, não apresenta um modelo de ensino. Os estudos da corrente Norte-Americana são centrados nos elementos de situação e deixam de lado as características formais dos gêneros, ou seja, visam apenas 
o modo com que os gêneros funcionam, sendo vistos como uma resposta a contextos externos, ou sociais, recorrentes em uma cultura.

O conceito de gênero nessa perspectiva é de que "as formas de comunicação reconhecíveis e auto-reforçadas emergem como gêneros" (BAZERMAN 2005, p.29). Quando se cria formas tipificadas ou gêneros, as situações das quais os gêneros emergem também são tipificadas (SOARES, 2009). Essa tipificação irá permitir dar forma e significado as diversas circunstancias, bem como atuará na orientação dos tipos de gêneros e de suas ações e, para que obtenhamos um entendimento profundo teríamos que ter a concepção de gênero configurando-se como "fenômenos de reconhecimento psicossocial que são partes de processo de atividades socialmente organizadas" (BAZERMAN 2005, p.31) e não apenas como um conjunto de traços textuais.

Centrado nos elementos de situação e no modo como os gêneros funcionam como respostas aos contextos, essa perspectiva apoia-se em uma visão de gênero como sendo dinâmico, possível de transformação e ao desaparecimento. Os estudiosos da escola Norte-Americana não propõe nenhum modelo de ensino, como visto na escola anterior e na que veremos a seguir, porém essa perspectiva defende alguns posicionamentos em relação ao ensino tendo como ponto de partida uma concepção de que "os gêneros que atuam na sala de aula são mais do que uma repetição de proposições padronizada" (BAZERMAN, 2005, p.30), logo a escola critica um ensino prescritivo e explícito das formas genéricas, tal como defende a perspectiva sistêmico-funcional da Escola de Sydney, pois este apontaria para uma visão de gêneros como algo estável e, também, enfatizaria os elementos textuais e linguísticos em detrimento das ações e práticas retóricas.

Assim, se visarmos um ensino prescritivo de gêneros isso acarretaria em um esvaziamento do sentido de atividades em sala de aula e transformaria as produções genéricas em exercício formal. Mas, para que exista dinâmica e para que os gêneros solicitados aos estudantes como produção se mantenham "vivos" nas situações de comunicação que ocorrem na escola, seria necessário tomar como base as experiências 
prévias dos alunos com os gêneros em situações sociais que eles considerem significativas, ou ainda, explorando o desejo do envolvimento em novas situações discursivas, como propõe a Escola de Genebra que veremos a seguir.

Segundo Bunzen (2004) para tal perspectiva - visando que o uso da língua escrita ocorra de modo dialógico e situado - os professores deveriam criar situações e estratégias para que os alunos produzissem e até inventassem novos gêneros com os quais funcionassem como uma resposta àquelas situações. Desse modo, no lugar do trabalho voltado para imitação de modelos genéricos, o foco deveria ser a desconstrução e a reconstrução desses modelos.

\section{Escola de Genebra}

Diferente das propostas anteriores - que adotam o conceito de gêneros como uma possibilidade de desestabilizar as práticas de ensino de língua materna consideradas "problemáticas" no que diz respeito à formação de sujeitos autônomos, preparados para inserção nas práticas letradas que se ocorrem dentro e fora do espaço escolar - o ensino do gênero para a Escola de Genebra tem grande repercução na educação brasileira.

Essa proposta integra a Teoria da Enunciação de Bakhtin e a Teoria da Aprendizagem de Vygotski, que deram aporte para o desenvolvimento e funcionamento da linguagem na perspectiva socio-interacionista. A Teoria Interacionista Socio-discursiva é um quadro teórico que entende as condutas humanas como "ações situadas cujas propriedades estruturais e funcionais são, antes de mais nada, um produto da socialização" (BRONCKART, 1997, p.13) e devido a essas condições externas de produção textual, ocorre um abandono da noção de "tipo de texto" e sim, a favor de gênero de texto (textual) e de tipo de discurso. Dessa forma, a perspectiva genebrina defende a "didática da diversificação" que segundo Bronckart e Schneuwly (2004) seria um movimento contrário às abordagens e aos métodos tradicionais que enfatizavam principalmente a abordagem puramente gramatical. Essa didática da diversificação seria então uma abordagem centrada na unicidade da língua, que seria a diversificação dos 
textos e as relações que os textos mantêm com o contexto de produção, dando lugar para os aspectos históricos e sociais. Logo, a interação dos alunos com textos de cunho histórico e social começou a ser levada em conta, bem como e a vivencia desses alunos antes da escola.

Aqui o gênero é visto com um instrumento para agir discursivamente, pois "aprender a falar e a escrever, então, é apropriar-se de instrumentos para realizar essas práticas em situações discursivas diversas, isto é, apropriar-se de gêneros". (Dolz \& Schneuwly, 1998, p. 65). Os gêneros não fornecem princípios para construir um currículo ou uma progressão, mesmo sendo a base do trabalho escolar, não servem para tal fim, pois "os gêneros são entidades vagas sem que possam ser identificados como uma só base em suas propriedades linguísticas" (BRONCKART, [1997], 1999). Além de que o trabalho com gêneros favorece o desenvolvimento das operações de linguagem que são construídas aos poucos, pois não está relacionada com uma competência textual inata. (Schneuwly, 1994).

Para por em prática a teoria adotada pela escola, foi proposto uma progressão curricular em espiral a qual deve ser trabalhada em todos os níveis de escolaridade, através de um ou mais gêneros. Dessa forma o que irá variar são os objetivos a serem atingidos em relação a cada gênero, com a finalidade de concretizar o domínio efetivo dos gêneros. Para que isso ocorra o trabalho escolar deverá ser organizado em uma sequencia didática, que é definida como "um conjunto de atividades escolares organizadas, de maneira sistemática, em torno de um gênero textual oral ou escrito" (DOLZ, SCHNNEUWLY, NOVARRAZ, 2004, p. 97). Essa sequência didática é dividida em: apresentação da situação, produção inicial, módulos e produção final.

\section{Métodos: semelhanças e diferenças}

Ao entrarmos em contanto com essas três propostas estrangeiras para o ensino de gêneros, algumas questões - mencionadas anteriormente - se sobressaem: Como organizar os gêneros em uma progressão que leve em conta o desenvolvimento e a 
Revista InterteXto / ISSN: 1981-0601

v. 7, n. $1(2014)$

aprendizagem dos alunos? Com quais objetivos a noção de gêneros é convocada ao cenário educacional? Quais gêneros, já que eles são múltiplos e heterogêneos, devem ser objetos de ensino na escola?

Diante dessas questões, cabem então algumas considerações acerca das perspectivas para o ensino dos gêneros defendidas por essas escolas estrangeiras.

\section{Tabela 1 - Comparação das Escolas}

\begin{tabular}{|c|c|c|c|c|}
\hline Escola & Perspectiva & |Proposta de Modelo de Ensino| & Ação & Gênero \\
\hline \multirow{4}{*}{ Sidney } & \multirow{4}{*}{$\begin{array}{l}\text { Linguística Sistêtmico- } \\
\text { Funcional - Para um Ensino de } \\
\text { Lingua Transdi sciplinar. }\end{array}$} & \multirow{4}{*}{ Ciclo de Ensino } & Negociaçãa do Tópico & \multirow{4}{*}{ 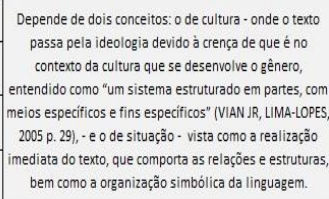 } \\
\hline & & & Desconstrução & \\
\hline & & & Construção Conjunta & \\
\hline & & & Construção Independente & \\
\hline \multirow{4}{*}{ Genebra } & \multirow{4}{*}{$\begin{array}{l}\text { Interacionista Socio- } \\
\text { Discursivo }\end{array}$} & \multirow{4}{*}{ Sequência Didática } & Apresentação da Situação & \multirow{4}{*}{ 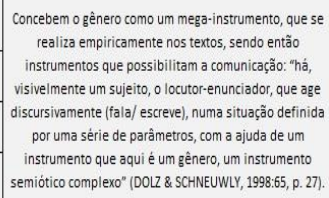 } \\
\hline & & & Produção Inicial & \\
\hline & & & Modúlos $[1,2, n]$ & \\
\hline & & & Produção Final & \\
\hline Norte-Americana & $\begin{array}{l}\text { Defende uma forma de } \\
\text { ensino centrada a partir dos } \\
\text { estudos retóricos }\end{array}$ & $\begin{array}{l}\text { Não popõe um modelo de } \\
\text { enisno, mas redefine o conceito } \\
\text { de gênero preocupando-se em } \\
\text { compreender de que modo os } \\
\text { gêneros funcionam como } \\
\text { resposta aos contextos sociais } \\
\text { recorrentes de uma determinada } \\
\text { cultura. }\end{array}$ & 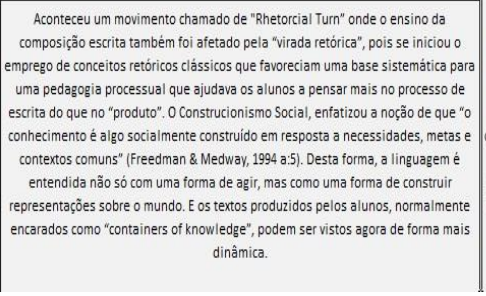 & 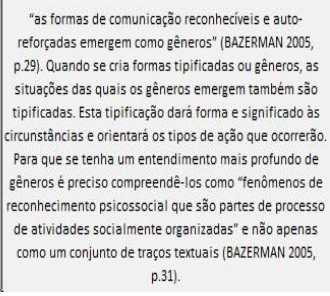 \\
\hline
\end{tabular}

FONTE: O autor. Escolas.

$\mathrm{Na}$ Tabela 1, pode ser visto algumas das diferenças e semelhanças entre as

Conforme vemos na tabela acima, para a escola de Sidney o ponto de vista adotado para o ensino dos gêneros é de um ensino de língua transdisciplinar, ou seja, a preocupação está em como a língua opera em todas as áreas do currículo escolar. O que sustenta tal posicionamento é a ideia de que para que os alunos consigam aprender os conteúdos escolares, eles precisam controlar os gêneros escritos mais valorizados nessa esfera comunicativa. Tal controle derivaria de um ensino explícito dos gêneros, o qual os auxiliaria tanto na participação efetiva das práticas de letramento escolar quanto nas práticas de leitura e escrita fora daquele ambiente, uma vez que muitas das exigências 
escolares no âmbito da linguagem - como argumentar, expor, relatar, explicar - também são requeridas em práticas de letramento que ocorrem além do âmbito escolar.

Ao propor tal modelo para o ensino de língua, os pesquisadores da Escola de Sydney enfatizam as possibilidades que este tem de configurar o currículo em termos de práticas de letramento relevantes dentro e fora do contexto escolar. Destacam também, o fato de o currículo poder ser organizado em espiral, levando em conta a progressão dos textos e sua complexidade, o que poderia facilitar o trabalho docente no que tange $o$ assessoramento aos alunos e aos critérios de avaliação dos textos por eles produzidos.

Em contrapartida, como observamos no modelo proposto pela Escola de Genebra, o movimento geral da sequência didática vai do mais complexo, - a produção inicial dos alunos - passando pelo mais simples - os módulos - e retorna ao complexo - a produção final dos estudantes - objetivando sempre o desenvolvimento de capacidades necessárias para o domínio dos gêneros.

Para a Escola Norte-Americana a identificação dos gêneros através de suas características textuais não é desprezada, todavia ela é vista como incompleta e enganadora. Enganadora porque atribui ao gênero características fixadas e atemporais, dessa forma ignora tanto o uso criativo da comunicação - para a satisfação de novas necessidades percebidas em novas situações, o que ocasiona mudanças, evoluções e, até mesmo, o desaparecimento de gêneros - quanto à transformação na maneira de entender os gêneros no decorrer do tempo. Incompleta porque não reconhece o papel dos sujeitos no uso e na construção de sentidos, além de desprezar as diferentes compreensões e percepções que as pessoas têm para os diferentes domínios comunicativos e, consequentemente, para os gêneros.

\section{Considerações finais}

Em primeira instância, ressaltamos a proposta da Escola de Sidney com seu modelo voltado a uma abordagem textual e com seu foco voltado na descrição da materialidade textual do gênero, deixando de lado às situações de produção, ou contexto, 
bem como os aspectos sociais e históricos envolvidos. Com essa abordagem, se pensarmos no contexto de educação brasileiro, poderíamos acabar restringindo o ensino dos gêneros à abordagem de seus aspectos linguístico-textuais, diminuindo a eficácia do ensino de produção de textos com características formais.

Ao que compete à proposta da Escola Norte-Americana, consideramos que o ensino de gêneros causaria certo esvaziamento na escrita dentro do contexto escolar. Ainda propõem que os gêneros deveriam ser enfocados a partir de seus padrões textuais e linguísticos, o que chama a atenção para a necessidade de considerarmos as experiências prévias que os alunos têm com os gêneros nas diversas situações sociais o que pode ser visto como ponto de partida para um ensino eficaz.

Com a visão Interacionista socio-discursiva da Escola de Genebra, tomando como escopo o contexto educacional brasileiro, teríamos certo avanço no ensino-aprendizagem, pois uma vez o sujeito inserido na proposta realizada pelo professor, ele se sentiria como parte daquele cotexto, mesmo que na sua volta existam outros sujeitos com aspectos sócio-históricos distintos. Podemos pensar ainda que a questão social que os estudiosos de Genebra propõe, quando bem realizadas pelo professor em sala, reafirmaríamos a ideia de que os gêneros tratados em sala de aula devem ser escolhidos conforme as situações escolares e que a escola deveria garantir o acesso aos gêneros de diferentes esferas, abordando-os não só em seus aspectos formais, mas, sobretudo, na sua dimensão sócio-histórica.

Embora a perspectiva da Escola de Genebra apresente certa hegemonia no Brasil, quando abordamos a questão do ensino dos gêneros, temos muito que fazer para conseguir obter um ensino que leve em conta à proposta de gêneros, sem o por como objeto de ensino, segundo ressalta Dolz e Schneuwly (2004), e sim utiliza-lo como ferramenta didática em sala de aula. Dessa forma, temos que ter em vista que tal perspectiva de interação com o gênero permite preparar os sujeitos para dominar a língua em situações variadas, fornecendo-Ihes instrumentos eficazes para desenvolver uma relação com o comportamento discursivo consciente e voluntário, favorecendo assim, as 
estratégias de auto-regulação. Ainda, ajudá-los a construir uma representação das atividades de escrita e de fala em situações complexas, como produto de um trabalho e de uma lenta elaboração.

A parte, o que propomos aqui foi uma breve discussão a respeito das perspectivas adotadas pelas escolas estrangeiras que contribuem para o ensino e aprendizagem tomando como ferramenta construtiva, o ensino do gênero.

\section{Referências}

ADAIR; MOTTA-ROTH Désirée.(orgs.). Gêneros: teorias, métodos, debates. São Paulo: Parábola Editorial, 2005.

BUNZEN, C. 2004. O ensino de "gêneros" em três tradições: implica-ções para o ensinoaprendizagem de língua materna. Letramento do professor. Disponível em: http://www.letramento.iel.unicamp.br/publicacoes/public_clecio/o_ensino_de_generos.html 1. Acesso em: 23/04/2014.

BRONCKART, Jean-Paul. Atividade de linguagem, textos e discursos : por um interacionismo sociodiscursivo. $1^{\text {a }}$ ed. Trad. Anna Rachel Machado. São Paulo, Educ, 1999.

BRONCKART, Jean-Paul. Atividades de Linguagens, texto e discursos. Por um interacionismo sócio-discursivo. Trad. Anna Rachel Machado e Péricles Cunha. São Paulo: Educ, 1997/99.

DOLZ, Joaquim; NOVERRAZ, Michèle e SCHNEUWLY, Bernad. Seqüências didáticas para o oral e a escrita: apresentação de um procedimento. In: DOLZ, J.; SCHNEUWLY, B. Gêneros Orais e escritos na escola. São Paulo: Mercado da Letras, 2004

ROJO, Roxane Helena Rodrigues (org). A prática de Linguagem em sala de aula: praticando os PCNs. São Paulo: Mercado das Letras, 2000. 
. Gêneros discursivos e textuais: questões teóricas e aplicadas. In: MEURER, J.L., BONINI,

VIAN JR. Orlando; LIMA-LOPES, Rodrigo E. A perspectiva teleológica de Martin para a análise dos gêneros textuais. In: MEURER, J.L., BONINI, Adair.; MOTTA-ROTH Désirée.(orgs.). Gêneros: teorias, métodos, debates. São Paulo: Parábola Editorial, 2005. 